\title{
O CONSELHO DE CLASSE COMO UM ESPAÇO DE CONTRADIÇÕES E FORMAÇÃO DO TRABALHO EDUCATIVO NO IF SERTÃO, CAMPUS PETROLINA
}

\author{
L. M. SILVA', B. L. BARROS JUNIOR E A. S. L. LATORRE ${ }^{2}$ \\ Instituto Federal do Sertão Pernambucano (IFSertão-PE) \\ E-mail: luzmoreira2009@gmail.com ${ }^{1}$; alessandra.latorre@ifsertao-pe.edu.br ${ }^{2}$
}

Artigo submetido em fevereiro/2014 e aceito em março/2014

\section{RESUMO}

O presente artigo trata de uma discussão sobre o Conselho de Classe como um espaço de contradições e formação do trabalho educativo no IF SERTÃO-PE, Campus Petrolina, na modalidade de ensino médio integrado. Partindo das observações e registros feitos nas reuniões do ano letivo de 2012, além de conversas com os educadores envolvidos e referencial teórico sobre educação técnico-profissionalizante foi possível identificar limites e avanços no processo de avaliação discente e considerações frente a 'dualidade estrutural' educacional brasileira e as exigências atuais do mundo do trabalho.

PALAVRAS-CHAVE: conselho de classe, ensino médio integrado, avaliação qualitativa

\section{THE CLASS COUNCIL AS A SPACE OF CONTRADICTIONS AND SHAPING OF EDUCATIONAL WORK AT IF SERTÃO-PE}

\begin{abstract}
This article is a discussion about the Class Council as a space of contradictions and shaping of educational work at IF SERTÃO-PE, Campus Petrolina, in the modality of integrated high school. Based on the observations and records made at the meetings in 2012, on conversations with educators involved in this process and theoretical
\end{abstract}

references on professional technical education it was possible to identify limitations and advances in students evaluation process that considers the 'structural duality' in Brazilian education and the demands of today's working world.

KEYWORDS: class council, integrated high school, qualitative evaluation 


\section{INTRODUÇÃO}

O trabalho educativo tem sido uma prática social impregnada de representações da realidade pedagógica da escola, tanto nos aspectos políticos, estruturais e gerenciais, como nas opções didáticas que incluem os conteúdos curriculares, as metodologias de ensino e o processo de avaliação.

O educador se defronta com todo tipo de conflito, contradições e, ao mesmo tempo, de possibilidades de formação. Assim por dizer as concebidas tradicionalmente e as de cunho progressistas, por não dizer ainda, as de perspectivas contemporâneas, sintonizadas em referenciais atuais do processo de ensino-aprendizagem, em que argumentos neurotecnológicos e espirituais pretendem dar conta de uma nova perspectiva de transmissão de informação e/ou conhecimento e /ou de sua produção, enfim, de uma perspectiva de formação humana, qual seja.

Nessa realidade dos processos educativos, delimitados para esta reflexão de formais, ou seja, dos de origem da cultura escolar tal como a conhecemos hoje, trataremos do instrumento de avaliação, Conselho de Classe. Portanto, tem-se como objetivo para tal investida, identificar determinações políticas e ideológicas que cercam esse instrumento, considerando seu formato particular situado em uma escola de ensino técnico profissionalizante.

O Conselho de Classe tem sido uma opção pedagógica para conhecer as formas como se tem encaminhado o processo de formação de uma turma e o desenvolvimento escolar do aluno individualmente e em grupo. É um espaço para a troca de informações entre professores e as equipes pedagógica e de gestão, apontando necessidades e avanços, mas especialmente, questões singulares da vida dos alunos e condições de aprendizagem.

A construção metodológica e estratégica do Conselho de Classe é definida entre os pares, e cada grupo de educadores possuem autonomia para os seus encaminhamentos, considerando as sugestões sobre a melhor maneira de contribuir com o desenvolvimento escolar dos alunos. Nesta direção, o Conselho tem servido para avaliar o aluno com ajuda de outros professores, além daquele responsável por determinado componente curricular em debate. Assim, espera-se que se amplie o contexto que envolve uma turma ou um aluno a ser avaliado. E neste sentido, ocupamse os seus membros de considerar aspectos afetivos, morais e sociais acerca das posturas e comportamentos dos alunos, além de seus limites e avanços sobre a aprendizagem dos conteúdos.

$E$ é neste processo que surgem alguns questionamentos possíveis de encontrar contradições e reducionismos nas abordagens e interpretações que pautam o conselho de classe. Por outro lado se ver uma oportunidade única de consolidar e negociar práticas pedagógicas significativas a serem socializadas entre os educadores. Contudo, essas possibilidades, por vezes se apresentam engendradas por uma desatualização do conhecimento pedagógico, fazendo com que alguns educadores atuem por uma superfície escorregadia e de reprodução de um senso comum derivado de uma prática pedagógica já superada, necessitando assim de intervenções por parte da equipe que os auxiliam na ressignificação de alguns conceitos e atitudes. Neste sentido, o Conselho de Classe amplia o sentido de avaliação e decisão e se torna, também, um espaço de formação para o educador.

Para melhor entender o papel do Conselho de Classe, seus limites, possibilidades e desafios encaminha-se nesta oportunidade, reflexões sob alguns aspectos que o rodeia, as política da 
educação profissional no país, o processo didático, sua metodologia/ contexto e as decisões e considerações construídas coletivamente.

Em busca de materializar as reflexões e discussões ora produzidas no texto, espera-se realizar este artigo considerando as experiências dos autores em participar do Conselho de Classe das turmas do Ensino Médio Integrado do Instituto Federal de Educação, Ciência e Tecnologia do Sertão Pernambucano - IF SERTÃO-PE, Campus Petrolina. E ainda, das anotações em cadernos próprios, acentuando questões relativas ao tratamento dado pelos membros do conselho sobre: avaliação, acompanhamento pedagógico e social individualizado, notas sobre comportamento, disciplina e relacionamento social, anotações na ficha individual do aluno, recortes nas falas dos professores e coordenadores e observações sobre o trabalho integrado ou não de docentes de diversas áreas, registrando a presença desses professores.

Durante as reuniões do ano letivo de 2012, os participantes foram informados do intuito das anotações/discussões e convidados pelos autores para participarem da construção do presente artigo. Contudo apenas os atuais autores sistematizaram o trabalho.

Por fim, as anotações foram discutidas com os autores a partir de um referencial que atendesse problemáticas da educação técnica profissionalizante e suas políticas, considerando que essas podem determinar escolhas, atitudes dos educadores e o cotidiano da escola.

\section{O CONTEXTO HISTÓRICO PEDAGÓGICO PARA O CONSELHO DE CLASSE NO IF SERTÃO-PE, CAMPUS PETROLINA}

Tratar sobre Conselho de Classe como um instrumento de avaliação dos processos educativos e dos sujeitos envolvidos requer, no mínimo, situar historicamente a escola e, na dinâmica do conselho, fazer uma reflexão sobre a prática pedagógica, identificando os limites e possibilidades da mesma. Além de ser um espaço para apreender as abordagens teóricas e metodológicas assumidas no trabalho escolar, qualificando a discussão entre os sujeitos que se defrontam com suas diferenças de discursos e concepções de mundo.

\subsection{Breve descrição da origem do Ensino Técnico Profissional}

Ao contextualizar uma escola de ensino técnico profissionalizante se identifica uma realidade atrelada ao bojo das contradições do mundo do trabalho, determinada em seu movimento, por políticas educacionais motivadas historicamente por diferentes projetos de sociedade.

Tenta-se neste breve apanhado sobre a origem desse tipo de escola, construir argumentos que representem um cenário possível de intercambiar hipóteses de que as políticas definidas para a educação técnica profissional possuem aspectos que interferem na avaliação e no debate promovido no interior dos Conselhos de Classe.

É pelo viés das políticas públicas para o ensino da educação técnica profissional que é possível afirmar, por exemplo, que há diferentes concepções de trabalhador e trabalhadora que atendem a projetos distintos de sociedade e, por esse confronto ideológico, o ensino técnico profissionalizante tem se constituído através de diretrizes e decretos que perfazem um conjunto 
de normatizações e fundamentos que balizam o trabalho de gestão e os encaminhamentos pedagógicos atuais dessas instituições.

Para compreender o mecanismo imposto por esses confrontos de classe à escola é necessário buscar na história a configuração social que define o caminho traçado pela educação brasileira, em especial, a educação técnica profissionalizante.

$\mathrm{Na}$ origem do ensino técnico profissional no país, datado de um século de existência, o processo educativo se apresentava como uma rede de Escolas de Aprendizes e Artífices que acolhiam as camadas pobres, os "desvalidos da sorte", ou jovens ociosos e excluídos do seio socioeconômico em um país que iniciava seus passos pelas novas transformações geradas na época pela ampliação do setor secundário e terciário.

Há exatamente pouco mais de um século atrás, o Brasil apontava para a necessidade de compor uma massa de trabalhadores que tenderiam ao trabalho pelas novas configurações comerciais e industriais que se vislumbrava na então criada República. Era um momento em que havia necessidade urgente para atender as novas demandas econômicas pela formação técnica profissional. No entanto, o que se conseguia em termos de políticas educativas era a instalação de escolas primárias que formavam os filhos da elite acumuladora de capital, enquanto que grande parte da população analfabeta servia de mão-de-obra barata para o aparato agrícola, e pouco qualificada para o sonho de indústrias que se firmava.

Nesse sentido, um problema concreto que se encontra no movimento constituído da educação brasileira se consolidava na feição de um projeto de formação de trabalhadores por dois seguimentos distintos, um com base em uma formação para a elite e outro para a grande parcela da população que estava excluída dos conhecimentos e saberes necessários para a participação e transformação social.

Caracterizava-se o problema da "dualidade estrutural", apontado por Kuenzer (2007) que representa hoje a dificuldade das escolas e das políticas públicas em definirem a integração dos diferentes componentes curriculares que compõem as áreas propedêutica e técnica que subsidiam a formação integral do trabalhador diante das imposições da lógica do mercado de trabalho, do trabalho assalariado, ou melhor, de uma práxis produtiva gerada pelo capitalismo e, das possibilidades reais e concretas de produção e incorporação de conhecimentos capazes de gerar desenvolvimento e qualidade de vida mediado por uma concepção de trabalho como práxis humana.

As reflexões acima têm marcado o debate e leva a compreensão de que a escola técnica profissional vem servindo para reproduzir a histórica divisão do trabalho e se ajusta ao modelo de produção atual que reestrutura o trabalho e o põe em condições precárias para atender as demandas socioeconômicas para a reprodução capitalista atual.

As políticas públicas que derivam os decretos e diretrizes para a educação técnico profissionalizante, a exemplo dos Decretos no 2.208/97 e o no 5.154/2004, são exemplos de uma disputa ideológica e de classe, assumidas politicamente pelos representantes conservadores e progressistas da sociedade brasileira contemporânea.

É por meio desses decretos, por exemplo, que podemos identificar um conjunto de forças que se confrontam em busca de caracterizar e constituir um modelo de ensino ideal para os trabalhadores brasileiros. No entanto, o que se percebe é que ainda há uma distância política para 
uma concreta e objetiva educação laica, unitária, democrática e politécnica. Vale ainda afirmar sobre a dificuldade em fazer acontecer um ensino médio integrado que relacione a educação básica e técnica-profissional.

Como exemplo prático que contribui para a compreensão dessa relação histórica é a forma como vem se desenvolvendo o Conselho de Classe no IF SERTÃO-PE, Campus Petrolina. Como apresentado acima, as reuniões necessariamente convocam os professores da área técnica e da propedêutica, contudo as listas de presença marcam a grande ausência dos primeiros no processo de avaliação, dificultando uma leitura mais completa e integrada, da realidade pedagógica dos cursos e limitando as avaliações e os encaminhamentos da formação pelos aspectos conhecidos da área propedêutica, impedindo estratégias mais eficientes de acompanhamento dos alunos e da turma.

Este exemplo indica claramente que o processo de integração entre educação básica e técnica, que formaria o trabalhador munido de conceitos científicos e tecnológicos básicos que Ihe dariam o sentido de força produtiva, está distante de se firmar, mesmo com o avanço da revogação do decreto no 2.208/97 pelo de no 5.154/2004 que restabelece a possibilidade de integração curricular dos ensinos médio e técnico.

\subsection{O Sistema didático referente ao Conselho de Classe}

Com base na divisão social do trabalho a educação no país se estrutura por um lado em um processo de formação intelectual apreendido em espaços reservados para os filhos da elite e, por outro, em um conjunto de práticas imediatas para suprir as demandas técnicas do trabalho mais simplificado para o resto da população.

Entre esses descaminhos educacionais, recai sobre a mesa dos educadores a difícil tarefa de encontrar soluções para dar conta dos conflitos gerados na formação de alunos do ensino médio integrado no IF SERTÃO-PE, Campus Petrolina. Parte dos problemas identificados no processo de educação de uma escola deste nível se encontra nas opções teórico-metodológicas encaradas pela equipe de educadores. Assim, busca-se fazer uma relação dessas perspectivas pedagógicas e os encaminhamentos pautados pela especificidade de ser uma escola federal técnica profissionalizante.

Nesse sentido, o recorte delimitado a partir do Conselho de Classe é significativo, na medida em que este é um espaço-ação que aglutina reflexões e discussões que encaminham decisões essenciais e representativas da concepção educativa e da missão institucional.

Dessa forma, para superar os desafios e as dificuldades apontadas em um Conselho de Classe, especialmente no contexto de uma escola de ensino técnico profissionalizante, não se trata de realizar, por exemplo, mudanças metodológicas simplesmente, mas de encontrar possibilidades em repensar e atuar pedagogicamente a partir de outra lógica, de outra compreensão de relações entre os sujeitos (SANTOS, 2003), em outros objetivos educacionais e de ciência, trabalho e cultura, trazendo o trabalho pedagógico para compor um projeto de nação e de sociedade, em direção contrária as referências da concepção neoliberal que propaga um projeto individual (RAMOS, 2010), em que a pessoa é a única responsável por suas conquistas e derrotas. Isso se apresenta no conselho de classe quando se atribui ao aluno toda a culpa pelo seu baixo desempenho escolar, ou ao contrário quando o aluno tem excelente desempenho e é reconhecido por todos como o exemplo de sucesso por ser "esforçado", "disciplinado" e "inteligente". 
O ponto de partida para uma análise sobre as abordagens teórico-metodológicas suscitadas nos debates do conselho recai sobre as referências avaliativas dos professores, e neste ponto, as tensões geradas parecem resultar da centralização do processo ensino- aprendizagem com base em avaliações quantitativas. Durante o conselho é possível identificar as opções dos professores em resumir o processo avaliativo no valor das notas, desconsiderando, por exemplo, a presença e produção do aluno durante as aulas. Ainda quando mencionam a participação do aluno nas aulas, o professor acaba propondo uma pontuação para a participação deste aluno e em outros critérios para chegar em um valor final.

Diante do exposto, o desafio que se apresenta é o de avaliar o aluno, considerando-o dentro de uma escola de ensino médio integrado, ou seja, com possibilidades reais de utilizar o conhecimento de forma integrada, sendo capaz de compreender a produção histórica e científica dos processos sociais e tecnológicos, buscando a consciência da realidade atual e suas contradições mediadas pelas relações de produção.

Este ponto crucial da formação humana apresenta o movimento histórico da produção do homem e, espera-se, localizar o aluno/trabalhador como sujeito capaz de incorrer nas transformações necessárias de seu mundo. Nesta direção, as referências avaliativas recorrem para a atualização dos saberes.

O Conselho de Classe se concretiza neste recorte avaliativo do processo ensinoaprendizagem, na medida em que o diálogo por diferentes sujeitos que se afirmam por diferentes tempos e espaços, por suas experiências pedagógicas e de vida, e assim, pelas diversas concepções de mundo e do reconhecimento de saberes necessários à prática educativa (FREIRE, 1996) e de saberes necessários à educação do futuro (MORIN, 2001).

Outros aspectos relevantes que surgem nas discussões do Conselho de Classe no IF SERTÃO$\mathrm{PE}$, Campus Petrolina se caracterizam por entender que o contexto escolar reflete a complexa relação entre professor-aluno-gestão-família-governo-mundo. Este aparato institucional vai se descortinando na medida em que são identificadas suas relações, mesmo que incipientemente. Mas ainda se espera que itens fundamentais que possam balizar a prática pedagógica e o trabalho educativo superem os desafios postos, contudo, sobre uma referência de sujeito e suas relações e de objetivos educacionais que considerem as contradições e mediações advindas do mundo produtivo.

Nas próximas seções do texto se encontra observações sobre o cotidiano escolar e como os sujeitos envolvidos manifestam suas representações e concepções do trabalho educativo nas discussões do Conselho de Classe. Questões como a relação da família com a escola, professoraluno, gestão e equipe pedagógica, além dos aspectos ligados ao processo de ensinoaprendizagem e objetivos educacionais.

\section{O CONSELHO DE CLASSE COMO UMA OPÇÃO DO TRABALHO ESCOLAR, SUA DINÂMICA, SUAS ESTRATÉGIAS E INTENÇÕES NO IF SERTÃO-PE, CAMPUS PETROLINA.}

O Conselho de Classe teve sua origem por volta de 1945, na França, com o intuito de orientar o acesso dos alunos ao ensino clássico ou técnico, conforme sua aptidão. Já na década de 50, o conceito foi trazido ao Brasil em consequência do Manifesto dos Pioneiros da Educação Nova 
acontecido em 1932, o qual se colocava contrário à centralização do poder de decisão e sugeria uma organização que valorizasse o trabalho coletivo, a discussão e a criação de novos métodos (CADERNO TEMÁTICO, 2008).

No IF SERTÃO-PE, Campus Petrolina o Conselho de Classe foi implantado em 2008 através de uma Resolução do Conselho Diretor do antigo CEFET Petrolina. Foi criado partindo do princípio explícito na Lei № 9394/96 - Lei de Diretrizes e Bases da Educação Nacional, que diz que a avaliação qualitativa deve se sobrepor à avaliação quantitativa. Dessa forma, pretendia-se valorizar a formação integral dos alunos reconhecendo suas diversas aprendizagens e repensando a prática pedagógica a partir das observações, discussões e reflexões feitas.

Ainda hoje, nota-se que nem todos os procedimentos descritos no documento são realizados, o que indica uma dificuldade em articular a teoria com a prática. Essa resolução prevê, por exemplo, a participação de representantes de alunos durante as reuniões do conselho de classe, o que nunca aconteceu por dificuldade em articular essa participação e estabelecer uma relação democrática entre professor e aluno.

Vale destacar que enquanto se discutia a implantação do conselho de classe de acordo com o estabelecido na resolução, vários problemas eram detectados no dia a dia como, por exemplo, as reprovações de alunos por faltar um ou alguns poucos décimos para contemplar a média, desconsiderando totalmente o desempenho qualitativo nos demais aspectos e componentes curriculares. Além disso, antes do conselho não se tinha registros sobre o desempenho dos alunos, de suas características e habilidades e até problemas de alguns alunos e/ou familiares, que acabavam afetando o processo educativo.

Diante desses e outros problemas, a coordenação pedagógica resolveu reunir os professores uma vez por bimestre com o objetivo de refletir sobre os problemas de cada curso, turmas e alunos, assim como os avanços e possibilidades de melhor desempenho uma vez que a troca de informações entre os docentes dos diversos componentes curriculares é algo relevante na orientação do processo de ensino-aprendizagem. Assim foi criada uma pasta para cada turma, contendo fichas individuais de cada aluno com aspectos como interesse, participação nas aulas, desempenho nas atividades, resolução de exercícios e outras observações. No início da reunião é feito um relato geral sobre o aproveitamento e características da turma e em seguida de cada aluno. Essas informações são registradas, assim como os encaminhamentos sugeridos pelos docentes e coordenação pedagógica.

Esses procedimentos têm sido de grande utilidade para o processo educativo do Ensino Médio Integrado do IFSERTÃO-PE, Campus Petrolina, pois em primeiro lugar esse procedimento serve de referência para o tão corriqueiro atendimento aos pais que na maioria das vezes que vão à escola querem saber sobre o desempenho escolar do filho e nem sempre encontram os docentes disponíveis para conversar. Em segundo lugar, com o passar do tempo é gerado um histórico da vida escolar do aluno e consequentemente constrói-se uma identidade do aluno, que pode ser positiva ou negativa a depender das concepções da equipe presente no conselho de classe. Assim, esse histórico individual do aluno pode ser visto como algo positivo à medida que enfatiza qualidades, avanços, aprendizagens e até problemas dos alunos, da família e comunidade em geral, que a depender da prática docente poderá aproveitar essas informações para estabelecer uma melhor relação com o aluno e planejar suas atividades de acordo com as características e realidade da turma, assumindo atitudes que favoreçam o bom aproveitamento dos alunos. 
Ao nortear o trabalho pedagógico, o Conselho de Classe pode incorrer por alguns aspectos negativos, quando emite por concepções tradicionais a sua função classificatória, rotulando os alunos e os dividindo entre "bons" e "ruins", "fracos" e "fortes", "disciplinados" e "indisciplinados", ou simplesmente atribuindo a responsabilidade do fracasso escolar somente ao próprio aluno. Este último ponto é bem visível quando diante de casos de alunos que alcançam notas bem abaixo da média é escrito na sua ficha individual a seguinte observação: "Precisa estudar mais". Esta anotação exime os docentes, a equipe pedagógica e a gestão da instituição de qualquer responsabilidade com o fracasso desses alunos.

Ainda cabe apontar nesse espaço que para a realização do conselho de classe existem muitas dificuldades, destacando a resistência de alguns docentes em participar, pois para alguns o conselho quer aprovar os alunos de qualquer forma, e para outros o conselho é "perda de tempo", pois não contribui com a aprendizagem dos alunos. Outra dificuldade encontrada é a efetivação das ações após as reuniões de conselho de classe pelas diversas áreas do Ensino Médio Integrado, diante da ausência de profissionais que assumam essa responsabilidade e que reconheçam essa atribuição como pertencente a um coletivo de professores, equipe pedagógica e de gestão, o que deixa em evidencia que o conselho de classe ainda não está explícito no fazer pedagógico institucional do IFSERTÃO-PE, Campus Petrolina.

\section{AS DECISÕES E CONSIDERAÇÕES PAUTADAS NO CONSELHO DE CLASSE DO IF SERTÃO, CAMPUS PETROLINA}

O conselho de classe desde sua implantação no IF SERTÃO-PE, Campus Petrolina, tem sido um espaço essencial para os educadores, na medida em que vem incluindo alunos que não tem um desempenho acadêmico satisfatório ou que apresentam qualquer outra situação que mereça um acompanhamento mais específico, no ritmo considerável para o processo de ensinoaprendizagem. Estas reuniões tem sido de muita valia, pois diminui o distanciamento existente no cotidiano entre professor-aluno e família.

A realidade vivida na escola e fora dela pelos alunos, em alguns momentos passa despercebida pelo professor e é num momento de conselho de classe que determinadas situações são colocadas, assim como qualquer evento não corriqueiro e diferente do habitual notado pelo professor é também trazido para o conselho.

As questões diretamente pedagógicas como, por exemplo, baixo rendimento e problemas de aprendizagem, que dependem da intervenção da coordenação e da atuação direta do professor, são mais facilmente resolvidas quando discutidas nas reuniões de conselho de classe, devido a uma maior aproximação entre a coordenação, os professores e os alunos. Para que se alcancem os objetivos do conselho de classe faz-se necessário um comprometimento do docente e também uma reflexão coletiva em relação às práticas adotadas como aulas extras e atendimento individual ao aluno para sanar dúvidas; o uso das tecnologias da informação e das redes sociais para uma aproximação maior e um melhor acompanhamento do aluno. Sem dúvidas, essas atividades e ações podem contribuir positivamente para que estes alunos tenham uma melhoria no seu desempenho acadêmico. 
Outro ponto a ser considerado é quando o conselho de classe detecta uma situação anômala com um determinado aluno, seja de natureza comportamental, cognitiva, econômica e/ou social etc., há a necessidade de um apoio de outras áreas da instituição para que haja um suporte na busca de soluções para a situação. Entretanto, o que tem sido percebido é uma falta de integração entre vários setores da instituição que deveriam estar ligados e agindo de forma conjunta, a exemplo, da assistência estudantil na representação do serviço social e da psicologia. Este fato, infelizmente, constitui uma fragilidade no trabalho educativo institucional.

É nessa perspectiva que se estabelece o Conselho de Classe como sendo uma reunião de "todos" os responsáveis pelos resultados com o propósito de análise e levantamento de possíveis medidas a serem tomadas posteriormente. O Conselho de Classe "[...] é o momento e o espaço de uma avaliação diagnóstica da ação pedagógico-educativa da escola, feito pelos professores e pelos alunos [...]". (CRUZ, 1995, p. 116). Esta última afirmativa aponta uma falha do conselho de classe do IF SERTÃO-PE, Campus Petrolina, já que este apesar de contribuir bastante com o processo educativo, não conta com a participação do aluno e por isso assume uma postura tradicional em que a figura do professor é quem decide todas as etapas do processo de ensinoaprendizagem.

Obviamente a formação de alunos não se faz apenas com professores como na concepção tradicional, é necessária a participação do aluno, da família e a interação de outros setores da comunidade educativa atuando coletivamente. A falta de interação entre os setores tem se tornado um entrave, pois o IF SERTÃO-PE - Campus - Petrolina, além de ser um espaço voltado na formação de profissionais cidadãos, tem seu papel de prepará-los para a vida, o que requer atenção especial por parte dos diversos setores de formação. Mais uma vez fica evidente que o processo educativo é uma missão de todos e quando isso não acontece, acaba fragilizando algumas ações, como é o caso do conselho de classe.

Os resultados dos conselhos de classe realizados no IF SERTÃO-PE, Campus Petrolina mostram também que para um melhor acompanhamento do aluno deve acontecer a parceria escola-família, porém o que é visto no trabalho diário é que muitas famílias não são presentes na escola, ou seja, na vida escolar do aluno e consequentemente não são atuantes, deixando que estes fiquem por conta de si mesmos. Muitos pais desconhecem as atividades e acontecimentos do ano escolar do seu filho e isso reflete negativamente no rendimento escolar do aluno. Ao mesmo tempo se pode perceber que pais que participam ativamente da vida escolar dos filhos, estes tem um melhor desempenho e o sucesso escolar é garantido. De acordo com Brilhante (2004) as dificuldades encontradas relacionadas com a aprendizagem e com o sucesso escolar são inúmeras. Por um lado, há uma espécie de sentimento de culpa dos pais, que se cobram por não conseguirem atender às necessidades dos filhos, e do outro lado, os filhos sentem-se abandonados pelos pais nas suas necessidades, e por fim a escola, que não consegue desempenhar o papel social para o qual foi designada.

Sendo assim, a escola pode colaborar com as famílias orientando-as sobre a necessidade de dedicar cuidados à educação dos filhos e auxiliando nas tarefas escolares. Conforme Yaegashi (2007) tanto a escola quanto a família deveriam tentar mudanças que Ihes permitissem responder adequadamente, no sentido de ajudar a criança, evitando maiores dificuldades e situações de estresses. 
Nesse sentido, a atuação do conselho vem aprimorar a relação aluno-professor-família, eliminando assim um distanciamento natural que há entre os mesmos. A interação dos diversos setores da escola é de fundamental importância para que o aluno tenha uma formação adequada e as questões que possam vir a interferir na formação do aluno sejam superadas, porém o que tem sido experimentado é que quando os professores voltam a se reunir para um novo conselho de classe, as questões antes debatidas, são novamente levantadas por permanecerem sem solução adequada.

Após essa discussão se constata que o Conselho de Classe é fundamental para a qualidade do desenvolvimento do trabalho escolar diante dos desafios impostos para alcançar um nível educacional capaz de promover mudanças profundas na sociedade, considerando todas as contradições impostas na formação do trabalhador brasileiro.

No entanto, diante das dificuldades apontadas se verifica a necessidade de repensar a estrutura, a dinâmica e as concepções presentes no Conselho, considerando, ainda, que por se tratar de uma instituição de formação técnica-profissionalizante, o mundo do trabalho deve ser considerado nas discussões de avaliação, especialmente pelas diferentes áreas de conhecimento que representam a divisão social do trabalho, pois a garantia de uma educação de qualidade pressupõe reconhecer diferentes saberes que assegurem a autonomia do individuo para gerir a sua própria existência em uma realidade bastante contraditória e determinada pelo desenvolvimento das forças produtivas e das relações de produção que estabelecem os modelos de educação e a formação do trabalhador. E neste sentido, um passo importante para a consolidação e legitimação do Conselho de Classe desta instituição é a inclusão dos estudantes em suas discussões e decisões. Emitindo a voz e a representação de suas inquietações, dificuldades, necessidades, críticas e superações/avanços.

\section{CONSIDERAÇÕES FINAIS}

Portanto, podemos perceber que o Conselho de Classe no IF SERTÃO-PE, Campus Petrolina é um importante instrumento de avaliação, mas para se consolidar como efetivo espaço de diálogo sobre os problemas localizados do processo educativo é preciso que os sujeitos envolvidos se reconheçam, essencialmente, no contexto da formação profissional, encarando as contradições do mundo do trabalho e assumindo a missão de integrar os diversos conhecimentos que servirão de base para a formação integral do trabalhador brasileiro.

Diferente do exposto acima, a escola corre o risco de reproduzir as orientações e diretrizes marcadas pelo projeto de reprodução capitalista, onde o trabalho incorre nas reestruturações advindas do atual modo de produção capitalista.

Acredita-se que a trilha percorrida pelos sujeitos atuais que fazem parte do Conselho de Classe do IF SERTÃO-PE, Campus Petrolina tem conduzido as ações com limitações que precisam ser superadas, considerando que esse instrumento avaliativo abrange diversas esferas da instituição e assume diversas concepções pedagógicas que levam a encaminhamentos e decisões como as descritas neste artigo. Mas há um potencial formativo nesse Conselho e aspectos avaliativos que apontam para uma reflexão e superação sobre as referências e perspectivas tradicionais de formação do sujeito. Neste sentido, espera-se que mudanças de posturas na prática 
docente, na gestão e na participação dos alunos e da comunidade no processo educativo seja o ponto de partida parta a transformação da escola.

\section{REFERÊNCIAS BIBLIOGRÁFICAS}

1. BRILHANTE, Érica Souto de Abreu. Relações Família - Escola: Sucessos e Fracassos. 2004. Disponível em:<http://www.psicopedagogia.com.br/artigos/artigo.asp?entrID=568>. Acesso em 21 maio 2008.

2. CADERNO TEMÁTICO. Conselho de Classe. Dezembro de 2008. Disponível em:<http://www.diaadiaeducacao.pr.gov.br/portals/pde/arquivos/2225-6.pdf >. Acesso em 30, maio, 2013.

3. CRUZ, C.H.C. Conselho de Classe e participação. Revista da Educação. AEC. Ano 24, no 94, jan/mar, 1995. p. 111-136.

4. FREIRE, Paulo. Saberes necessários à prática educativa. São Paulo: Paz e Terra, 1996. KUENZER, Acácia Zeneida. Ensino Médio e Profissional: as políticas do Estado

5. neoliberal. 4a Ed. São Paulo: Cortez, 2007

6. MANFREDI, Silvia Maria. Educação Profissional no Brasil. São Paulo: Cortez, 2002

7. MONRIN, Edgar. Os sete Saberes Necessários à Educação do Futuro 3a. ed. - São Paulo Cortez; Brasília, DF: UNESCO, 2001

8. RAMOS, Marize. A relação da educação profissional e tecnológica com a universalização da educação básica. (In): MOLL, Jaqueline(Org.). Educação Profissional e Tecnológica no Brasil Contemporâneo. Porto Alegre: Artmed, 2010.

9. SANTOS, Akiko. Didática sob a ótica do pensamento complexo. Porto Alegure: Sulinas, 2003.

10. YAEGASHI, S.F.R. Família, Desenvolvimento e Aprendizagem Escolar: Um olhar Psicopedagógico. In: ROSIN, S.; MONTEIRO, E. Infância e Práticas Educativas. Maringá: EDUEM, 2007. 